\title{
First-in-human phase 1 of YS110, a monoclonal antibody directed against CD26 in advanced CD26-expressing cancers
}

Eric Angevin ${ }^{*}{ }^{1}$, Nicolas Isambert ${ }^{2}$, Véronique Trillet-Lenoir ${ }^{3}$, Benoit You ${ }^{3}$, Jérôme Alexandre ${ }^{4}$, Gérard Zalcman ${ }^{5}$, Philippe Vielh ${ }^{6}$, Françoise Farace ${ }^{6}$, Fanny Valleix ${ }^{7}$, Thomas Podoll ${ }^{8}$, Yu Kuramochi $^{9}$, Itaru Miyashita ${ }^{9}$, Osamu Hosono ${ }^{10}$, Nam H Dang ${ }^{11}$, Kei Ohnuma ${ }^{12}$, Taketo Yamada ${ }^{13,14}$, Yutaro Kaneko ${ }^{15}$ and Chikao Morimoto ${ }^{12}$

${ }^{1}$ Gustave Roussy, Université Paris-Saclay, Drug Development Department (DITEP), Villejuif, France; ${ }^{2}$ Centre Georges-François Leclerc, Unité de Phases Précoces, Dijon, France; ${ }^{3}$ Institut de Cancérologie des Hospices Civils de Lyon, CITOHL, Lyon, France; ${ }^{4}$ Hôpital Cochin, Paris, France; ${ }^{5}$ Centre Hospitalier Universitaire (CHU) de Caen, Centre de Recherche Clinique/Essais de phases précoces, Caen, France; ${ }^{6}$ Gustave Roussy, Translational Research Laboratory, Villejuif, France; ${ }^{7} \mathrm{FV}$ Clinical subcontractor for SynteractHCR SAS, Levallois-Perret, France; ${ }^{8} Y^{\prime}$ s therapeutics Inc., Redwood City, CA, USA; ${ }^{9}$ Kissei Pharmaceutical Co., Ltd, Tokyo, Japan; ${ }^{10}$ Department of Rheumatology and Allergy, IMSUT Hospital, The Institute of Medical Science, The University of Tokyo, Tokyo, Japan; ${ }^{11}$ Division of Hematology/Oncology, University of Florida, Gainesville, FL, USA; ${ }^{12}$ Department of Therapy Development and Innovation for Immune Disorders and Cancers, Graduate School of Medicine, Juntendo University, Tokyo, Japan; ${ }^{13}$ Keio University School of Medicine, Tokyo, Japan; ${ }^{14}$ Saitama Medical University, Saitama, Japan and ${ }^{15} Y^{\prime}$ s AC Co., Ltd, Tokyo, Japan

Background: YS110 is a humanised IgG1 monoclonal antibody with high affinity to the CD26 antigen. YS110 demonstrated preclinical anti-tumour effects without significant side effects.

Methods: This FIH study was designed to determine the maximal tolerated dose (MTD) and recommended phase 2 dose (RP2D) to assess the tolerance, pharmacokinetics (PK) and pharmacodynamics profiles of YS110 and preliminary efficacy. YS110 were initially administered intravenously once every 2 weeks (Q2W) for three doses and then, based on PK data, once every week (Q1W) for five doses in patients with CD26-expressing solid tumours.

Results: Thirty-three patients (22 mesothelioma) received a median of 3 (range 1-30) YS110 infusions across six dose levels $\left(0.1-6 \mathrm{mg} \mathrm{kg}^{-1}\right)$. MTD was not reached and two dose-limiting toxicities (infusion hypersensitivity reactions) led to the institution of a systemic premedication. Low-grade asthenia (30.3\%), hypersensitivity (27.3\%), nausea (15.2\%), flushing (15.2\%), chills (12.1\%) and pyrexia (12.1\%) were reported as ADRs. Pharmacokinetic parameters ( $A \cup C$ and $C_{\max }$ ) increased in proportion with the dose. sCD26/DPPIV assays indicated CD26 modulation. Prolonged stable diseases were observed in 13 out of 26 evaluable patients.

Conclusions: YS110 is well tolerated up to $6 \mathrm{mg} \mathrm{kg}^{-1} \mathrm{Q} 1 \mathrm{~W}$, which has been defined as the RP2D, with encouraging prolonged disease stabilisations observed in a number of patients with advanced/refractory mesothelioma.

$\mathrm{CD} 26$ is a $110-\mathrm{kDa}$, type II transmembrane glycoprotein with known dipeptidyl peptidase IV (DPPIV, EC 3.4.14.5) activity in its extracellular domain and is capable of cleaving N-terminal dipeptides with either L-proline or L-alanine at the penultimate position (Torimoto et al, 1992; Ohnuma et al, 2008). CD26 activity is dependent on cell type and the microenvironment factors that 
can influence its multiple biological roles (Havre et al, 2008; Ohnuma et al, 2011). Robust evidence from our accumulating data indicates that CD26 has an important role in T-cell biology and overall immune function (Morimoto et al, 1989; Tanaka et al, 1993; Morimoto and Schlossman, 1998; Dang et al, 1990a, b; Hegen et al, 1997; Ohnuma et al, 2008).

CD26 is also expressed on various tumours such as malignant pleural mesothelioma (MPM), renal cell carcinoma (RCC), colorectal cancer (CRC), hepatocellular carcinoma, lung cancer, prostate cancer, gastrointestinal stromal tumour, thyroid cancer and haematologic malignancies such as T-anaplastic large cell lymphoma, T-lymphoblastic lymphoma and T-acute lymphoblastic leukaemia (Havre et al, 2008).

Our previous work demonstrated that CD26 is preferentially expressed in MPM cells but not in normal mesothelial cells (Amatya et al, 2011), and suggested that membranous expression of CD26 is of potential importance in the treatment of MPM patients (Aoe et al, 2012). More recently, we demonstrated that the CD26-positive population of $\mathrm{CD} 24^{+} \mathrm{CD} 9^{+}$MPM cells exhibits the cancer stem cell features (Ghani et al, 2011; Yamazaki et al, 2012). We also reported robust in vivo data on the anti-tumour activity of anti-CD26 mAb in mouse xenograft models (Ho et al, 2001; Inamoto et al, 2006, 2007; Okamoto et al, 2014; Yamamoto et al, 2014).

YS110 is a recombinant DNA-derived humanised monoclonal antibody that selectively binds with high affinity to the extracellular domain of CD26.

The antibody is an IgG1 kappa with a molecular weight of $144 \mathrm{kDa}$ and was humanised via an in silico design based on the amino-acid sequence of anti-human CD26 murine mAb (14D10), which inhibited tumour cell growth, migration and invasion, and enhanced survival of mouse xenograft models (Inamoto et al, 2006). The gene of YS110 is deposited to ATCC in designated with accession No. PTA-7695. The gene is preserved in $\mathrm{DH} 5 \alpha$ Escherichia coli with plasmid having insert of heavy and light chain of a humanised monoclonal antibody against human CD 26 cDNA. The strain designation is S604069. YST-pABMC 148 $(\times 411)$. YS110 is produced by fermentation in mammalian cell (Chinese hamster ovary) suspension culture with the Glutamine Synthetase Expression System. In vitro pharmacological evaluation of YS110 demonstrated its selective binding to human CD26 on a number of human cancer cell lines and tissues, and no evidence for immune activation and no effect on DPPIV activity, while exhibiting direct cytotoxic effect on certain human CD26-positive cancer cell lines (Inamoto et al, 2006). In addition to antibody-dependent cellular cytotoxicity and complement-dependent cytotoxicity (Inamoto et al, 2006), YS110 induces tumour cell lysis in vitro via alternative original mechanisms: (i) a direct anti-tumour effect through the induction of cell cycle arrest by induction of $\mathrm{p} 27^{\text {kip } 1}$ expression (Inamoto et al, 2006, 2007), (ii) following internalisation of the CD26-YS110 complexes, an inhibition of invasion and migration of tumours cells by decreased binding to the collagen/fibronectin microenvironment matrix (Inamoto et al, 2006, 2007) and (iii) the nuclear translocation of CD26 molecules by internalisation of the CD26-YS110 complexes to inhibit proliferation of MPM cells via suppression of POLR2A gene expression (Yamada et al, 2013). In further studies using preclinical models, in vivo administration of YS110 resulted in inhibition of tumour cell growth, migration and invasion, and enhanced survival of mouse xenograft models inoculated with RCC or MPM (Inamoto, et al, 2007; Okamoto et al, 2014; Yamamoto et al, 2014).

In addition to our robust in vitro and in vivo data on antibodymediated dose-dependent tumour growth inhibition, YS110 exhibited excellent safety and pharmacological profiles in nonhuman primate models using single and repeated increasing intravenous doses. Considering the lack of T-cell proliferation and cytokine production in vitro, YS110 was therefore considered not to have an agonistic nor activating effect on human CD26-positive lymphocytes.

This first-in-human phase 1 clinical trial aims to evaluate the safety, pharmacokinetic/pharmacodynamic profiles and preliminary anti-tumour effects of YS110 in patients with CD26-expressing solid tumours and, particularly, refractory malignant mesothelioma, a tumour type in which successful therapeutic advances are expected to be warranted for a long time.

\section{MATERIALS AND METHODS}

Patients. Eligible patients were 18-80 years old with locally advanced, inoperable or refractory solid tumours that were histologically documented to express the CD26 molecule. Cancer histologies included mesothelioma (pleural or peritoneal) or other solid tumours such as non-small-cell lung carcinoma, RCC or hepatocellular carcinoma. All patients were in relapse following or were refractory to prior standard therapies (regardless of the number of prior treatment lines), with a progressive evaluable/ measurable disease. Other key inclusion criteria included Eastern Cooperative Oncology Group (ECOG) performance status score $\leqslant 2$, adequate bone marrow, liver and renal function; at least 4 weeks from prior surgery, chemotherapy, external radiotherapy or immunotherapy (at least 6 weeks from prior nitrosoureas). All patients provided written informed consent. This study was conducted according to the Declaration of Helsinki and was approved by an ethics committee and the French National Drug Agency.

CD26 immunohistochemistry screening. Analysis of CD26 tumour expression for pre-screening was performed centrally at Gustave Roussy by conventional immunohistochemistry performed on formalin-fixed paraffin-embedded (FFPE) archival tumour samples using a anti-human CD26 goat polyclonal antibody (AF1180, R\&D Systems, Minneapolis, MN, USA) as previously described (Aoe et al, 2012). Briefly, all patients were pre-screened for confirmed CD26-positive expression, defined as $\geqslant 20 \%$ of the tumour cells $(1+, 2+$ or $3+$ intensity) and verified independently by two pathologists ( $\mathrm{P}$ Vielh and $\mathrm{T}$ Yamada) (Figure 1).

Study design. This first-in-human study was designed as a classical $3+3$ dose-escalating phase 1 trial of the single agent YS110 (Supplementary Table 1). The primary objective was to determine the maximum tolerated dose (MTD) based on the occurrence of dose-limiting toxicity (DLT) and a recommended phase 2 dose (RP2D). Initially, cohorts $1-4$ each planned to enrol 3 , and up to 6 , patients sequentially to evaluate escalating YS110 doses at $0.1,0.4,1$ and $2 \mathrm{mg} \mathrm{kg}^{-1}$ for a total of three infusions of YS110 on days 1, 15 and 29 (one treatment cycle, Q2W). On the basis of preliminary pharmacokinetics $(\mathrm{PK})$ data, the protocol was then subsequently amended to allow patients to receive a total of five infusions of YS110 on days 1, 8, 15, 22 and 29 (one treatment cycle, Q1W) at 2, 4, and $6 \mathrm{mg} \mathrm{kg}^{-1}$. Each cohort included a $24-\mathrm{h}$ monitoring period following each infusion during the first cycle for evaluation of safety, DLTs and PK. Patients who completed one cycle and demonstrated a clinical response or stable disease could receive the second cycle of YS110 treatment cycles at the same dose and dosing frequency, until disease progression or a significant observed serious adverse event (SAE). If the patient continued the treatment, the second cycle was to begin initially 4 weeks (later amended to 2 weeks) after the last infusion of the first cycle (initially Day 57; after amendment, Day 43). For the subsequent cycles, the latency period between the last administration of a cycle and the beginning of the next cycle was 2 weeks. Secondary objectives of the study were to assess the safety and tolerability 


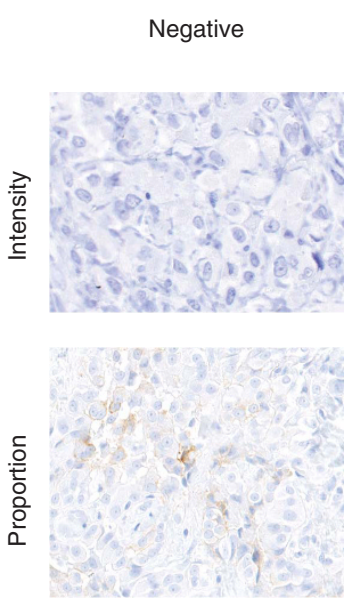

$0-10 \%$
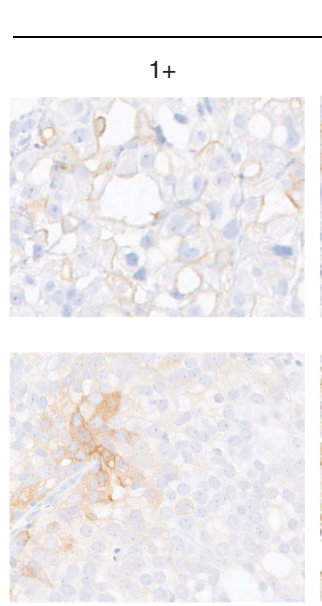

$10-20 \%$
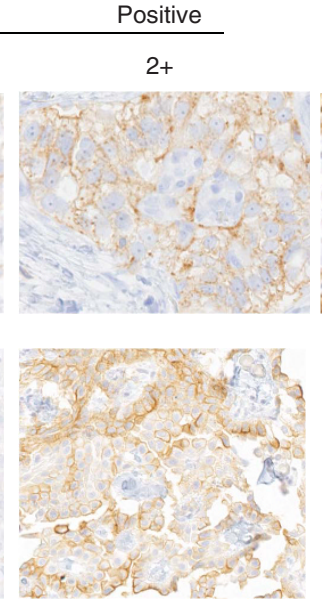

$20-60 \%$
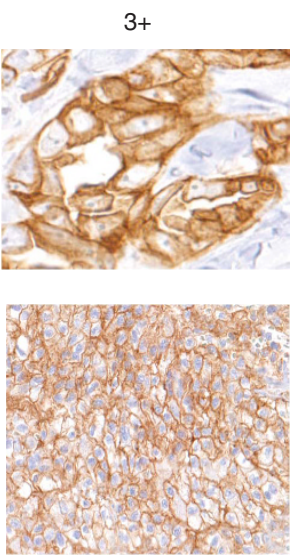

$60-100 \%$

Figure 1. Evaluation of CD26 staining by immunohistochemistry in cases of mesothelioma.

profile, $\mathrm{PK}$, pharmacodynamics, preliminary anti-tumour activity and to collect survival data.

Safety. All adverse events and SAEs occurring from the informed consent signature up to 30 days after the last dose were reported according to the National Cancer Institute Common Terminology Criteria for Adverse Events (CTCAE v3.0). An adverse drug reaction $(\mathrm{ADR})$ was defined as an adverse event $(\mathrm{AE})$ documented as possibly, probably or definitely related to the study drug or with unknown relationship to the study drug. A treatment-emergent adverse event was defined as an AE with onset on or after the first infusion. The DLT period was 2 weeks after the first YS110 infusion, whatever the dose schedule. Dose-limiting toxicities were defined as any grade $\geqslant 3$ non-haematological toxicity or a haematological toxicity of grade $\geqslant 4$. This definition was later amended to exclude reversible grade 3 infusion reactions defined as allergic reaction/hypersensitivity, fever, pain, bronchospasm, wheezing or hypoxia, occurring during the first dose infusion and resolving with a reduced infusion rate, a stop of the infusion, supportive care and/or the administration of corticosteroids (Supplementary Table S2). In case of treatment discontinuation due to reversible grade 3 infusion reactions, the patient was to be replaced with a new patient of the same cohort.

Efficacy. Preliminary clinical efficacy was evaluated by radiological and tumour marker assessments performed at screening at Day 43 of each treatment cycle, and at end of treatment until progressive disease (PD) or withdrawal of consent. Tumour response was evaluated based on RECIST 1.0 criteria and defined as partial response (PR) or PD or stable disease (SD). Partial response was defined as $\geqslant 30 \%$ decrease in the sum of the longest diameter (LD) of target lesions, PD was defined as $\geqslant 20 \%$ increase in the sum of the LD of target lesions and stable disease was defined as neither sufficient shrinkage to qualify for PR nor sufficient increase to qualify for PD. Patients with mesothelioma were assessed according to modified RECIST criteria.

Pharmacokinetics. Serial blood samples were obtained at pre- and post-YS110 administration at Day 1, Day 8, Day 15 and Day 29 at specified time points throughout the study. Serum levels of YS110 were analysed by ELISA by Alta Intertek (San Diego, CA, USA). The method of blood sample collection is described in Supplementary Information.

Pharmacodynamics. All treated patients with appropriate post baseline samples were evaluable for pharmacodynamics analyses on blood samples collected at days 0 (baseline), 1 (post infusion), 2, 15 (pre- and post infusion), 29 (pre- and post infusion) for immunomonitoring and soluble CD26 (sCD26)/DPPIV (sDPPIV) activity assessments.

Immunomonitoring. Immunomonitoring was performed centrally in the translational research laboratory at Institut Gustave Roussy, France (F Farace).

Immunophenotyping was performed for the monitoring of peripheral blood lymphocyte (PBL) $\mathrm{CD}_{2} 6^{+} \mathrm{T}$ (i.e., $\mathrm{CD}{ }^{+} \mathrm{CD} 4^{+}$, $\mathrm{CD}^{+}{ }^{+} \mathrm{CD} 8^{+}$) and $\mathrm{NK}$ (i.e., $\mathrm{CD} 3^{-} \mathrm{CD} 16^{+/-} \mathrm{CD} 56^{+}$) subpopulations by flow cytometry using fluorochrome-conjugated commercially available specific $\mathrm{mAbs}$ with relevant isotypic controls (all provided from Pharmingen, San Diego, CA, USA). To ensure the specificity of the CD26 staining in blood samples collected under YS110 treatment, competition and cross-blocking experiments using the two different CD26 mAb clones 5K78 (Santa Cruz Biotechnology, Inc., Dallas, TX, USA) and M-A261 (BD Pharmingen, San Jose, CA, USA) were also performed.

Dosages of serum cytokines (i.e., interleukin 6 (IL-6), tumour necrosis factor $\alpha$ (TNF- $\alpha$ ) and IL-2) were investigated by standard commercially available ELISA assays (R\&D Systems).

Soluble CD26 (sCD26) and DPPIV activity assessments. Assays for soluble CD26 and DPP4 were developed in the Morimoto's Laboratory (Juntendo University, Japan) using anti-human CD26 murine mAbs that exhibit no cross-reactivity with the therapeutic humanised anti-CD26 mAb YS110 as described previously (Dong et al, 1998; Ohnuma et al, 2015a). The sampling times for sCD26 were identical to that for immunomonitoring.

Statistical analyses. Descriptive statistics were used to summarise the data. The patient sampling size was a function of the $3+3$ dose escalation schedule. The realised sample size was dependent on the number and pattern of observed DLTs. The maximum sample size was a consequence of the design's sampling requirements and the number of dose levels. In this trial with six dose levels, the maximum number of patients being exposed in each dose level was determined according to the DTL occurrence rate and confirmation of safety.

\section{RESULTS}

Screening for CD26 expression. A total of 136 patients signed an informed consent form and were screened for CD26 expression on a FFPE archival tumour tissue sample. Mesothelioma, which was previously reported as one of the CD26-expressing tumour types 
was a main target indication with 60 patients screened $(n=60$, $53 \%$ were $\mathrm{CD}_{2} 6^{+}$cases). Examples of CD26 immunohistochemistry and scoring are presented in Figure 1. Other tumour types screened included RCC ( $n=18,71 \% \mathrm{CD}^{2} 6^{+}$cases $)$, hepatocellular carcinoma ( $n=7,22 \% \mathrm{CD}^{2} 6^{+}$cases) and various other tumour types $\left(n=31,13 \% \mathrm{CD}^{2} 6^{+}\right.$cases). Overall, $56(41 \%)$ patients were considered as $\mathrm{CD}_{2} 6^{+}$with the mean percentage of CD26 expression on tumour cells of $69 \%$ (range 20-100\%) in the tested samples.

Patient characteristics. Thirty-four $\mathrm{CD}^{+} 6^{+}$patients $(19$ males and 15 females) were enroled in the study and treated at 5 investigational sites in France, with 33 patients being evaluable (19 males and 14 females). The most common tumour types were mesothelioma $(n=23,69.7 \%), \operatorname{RCC}(n=9,27.3 \%)$ and one patient had an urothelial carcinoma $(n=1 ; 3.0 \%)$. All mesothelioma patients were diagnosed with the epithelioid histology and were all in advanced inoperable disease or refractory to previous line of treatment. Other tumour types were in stage III/IV Twenty-two patients were treated according to the Q2W schedule at $0.1(n=3)$, $0.4(n=3), 1(n=6)$ and $2 \mathrm{mg} \mathrm{kg}^{-1}(n=10)$ and 11 according to the Q1W schedule at $2(n=4), 4(n=3)$ and $6(n=4) \mathrm{mg} \mathrm{kg}^{-1}$ (Table 1). The median percentage of $\mathrm{CD}^{+} 6^{+}$tumour cells in archival samples from the patients treated was 63\% (range 25-100\%).

Safety. Eighteen patients received at least one cycle of YS110 with three infusions per cycle and seven patients completed at least one cycle with five infusions per cycle. Nine patients did not complete the first cycle.

During the DLT observation period (i.e., 15 days following the first infusion), two DLTs were reported as serious unexpected adverse events (SUSARs) consisting of grade 3 infusion reactions (one patient at the Q2W $1 \mathrm{mg} \mathrm{kg}^{-1}$ dose level and another patient at the Q2W $2 \mathrm{mg} \mathrm{kg}^{-1}$ dose level) that completely resolved with supportive treatment, but led to permanent discontinuation of treatment. As both patients had a history of allergies, consequently, the protocol was subsequently amended to add clinically relevant allergies as a new excluding criterion, as well as the administration of a systematic steroid prophylaxis prior to each infusion to better control potential infusion reactions (chills, fever, flushing, hypotension and respiratory disorders). With these modifications, dose escalation was possible up to $6 \mathrm{mg} \mathrm{kg}^{-1}$ in four patients without DLTs. Per protocol, dose escalation was stopped at the highest level of $6 \mathrm{mg} \mathrm{kg}^{-1}$ without the MTD being achieved.

All patients had one or more AEs and 113 ADRs considered to be possibly related to YS110 were reported by 30 (90.9\%) patients. The most frequently reported AEs regardless of potential relationship to YS110 were asthenia (54.5\%) and aggravation of prior conditions (30.3\%). Adverse effects (related or not to treatment) occurring in more than $10 \%$ of the patients are reported in Table 2 according to system organ class and preferred term. The majority of AEs were of mild (grade 1) or moderate (grade 2) severity. The most commonly reported grade $\geqslant 3$ AEs were dyspnoea $(21.2 \%)$, hypersensitivity (15.2\%), aggravation of prior conditions (15.2\%), general physical health deterioration (12.1\%) and hyperglycaemia (12.1\%). Eight patients (24.2\%) discontinued YS110 due to adverse events; most adverse events leading to discontinuation were considered unrelated to YS110, except for the two patients with infusion reactions considered as DLTs. Twenty-seven SAEs were reported in this study in 18 patients. Except for the two DLTs, all other SAEs, most commonly general physical health deterioration, were considered to be unrelated to YS110 but rather related to consequences of disease progression as assessed by the investigator, including the six patient deaths during the study.

No dose-dependent AEs were observed. Low-grade asthenia (30.3\%), hypersensitivity (27.3\%), nausea (15.2\%), flushing (15.2\%), chills $(12.1 \%)$ and pyrexia $(12.1 \%)$ were reported as ADRs.

No clinically significant abnormalities were observed in haematology and clinical chemistry laboratory parameters, as well as in ECG findings.

The main limiting toxicities in the study were infusion reactions, two being considered as DLTs leading to permanent discontinuation of treatment. Six severe hypersensitivity reactions were reported in five patients receiving a dose of $2.0 \mathrm{mg} \mathrm{kg}^{-1}$ and a severe anaphylactic reaction was reported in one patient receiving a dose of $1.0 \mathrm{mg} \mathrm{kg}^{-1}$. These ADRs, occurring mainly at the first infusion, were reversible and manageable with curative corticosteroids and antihistaminic drugs, and further prevented by a systemic corticosteroids premedication. Overall, these ADRs that did not appear to be related either to the dose level of YS110 or to the Q2W or Q1W schedule.

Pharmacokinetics. Following single and repeat intravenous infusions of YS110, there was a trend toward decreasing clearance (CL), increasing half-life time $\left(T_{1 / 2}\right)$ and increasing exposure $\left(C_{\max }\right.$, $\left.\mathrm{AUC}_{0-168}, \mathrm{AUC}_{0-\infty}\right)$ with increasing doses, suggesting that $\mathrm{CL}$ was saturating across the dose range studied. Mean volume of distribution $\left(V_{\mathrm{z}}, V_{\mathrm{ss}}\right)$ was similar or slightly higher than human serum volume, indicative of YS110 being primarily found in serum and consistent with prior observations for monoclonal antibodies. In general, exposure increased as the dose increased. Although increases in $C_{\max }$ appeared to be dose proportional, increases in $\mathrm{AUC}_{0-168}$ and $\mathrm{AUC}_{0-\infty}$ were greater than dose proportional, and this was consistent with the trend of decreasing CL with increasing doses (Table 3). In addition, YS110 PK parameters changed with repeat dosing. For doses ranging from 1 to $6 \mathrm{mg} \mathrm{kg}^{-1}$, mean CL was $\sim 1.1-1.6$-fold higher on Day 1 ( $v s$ Day 29), whereas mean $T_{1 / 2}$ increased $\sim 1.2-2.3$-fold and exposure $\left(\mathrm{AUC}_{0-168}\right)$ increased 1.3-1.8-fold on Day 29 vs Day 1 (Table 3).

Table 1. Baseline demographics and disease characteristics

\begin{tabular}{|c|c|c|c|c|c|c|c|c|}
\hline \multicolumn{2}{|l|}{ Number of patients $(n=33)$} & \multicolumn{7}{|c|}{ Schedule and dose levels ( $\mathrm{mg} \mathrm{kg}^{-1}$ ) } \\
\hline ECOG PS 0/1/2 (\%) & $29 / 58 / 13$ & & & & & & & \\
\hline Primary tumour type, $n(\%)$ & & 0.1 & 0.4 & 1 & 2 & 2 & 4 & 6 \\
\hline Mesothelioma (Meso) & $22(67)$ & 3 & 2 & 2 & 6 & 3 & 2 & 4 \\
\hline Median number of prior therapies (min-max) & $3(1-11)$ & & & & & & & \\
\hline
\end{tabular}


Table 2. Adverse events (all grades) reported by $\geqslant 10 \%$ of patients overall in any cohort

Dose levels $\left(\mathrm{mg} \mathrm{kg}^{-1}\right)$

\begin{tabular}{|c|c|c|c|c|c|c|c|c|}
\hline $\begin{array}{l}\text { Preferred term (CTCAE v3) number } \\
\text { of patients (\%) }\end{array}$ & $\begin{array}{c}0.1 \\
(n=3)\end{array}$ & $\begin{array}{c}0.4 \\
(n=3)\end{array}$ & $\begin{array}{c}1.0 \\
(n=6)\end{array}$ & $\begin{array}{c}2.0 \\
(n=14)\end{array}$ & $\begin{array}{c}4.0 \\
(n=3)\end{array}$ & $\begin{array}{c}6.0 \\
(n=4)\end{array}$ & $\begin{array}{l}\text { All AEs/grade 3-4 } \\
(n=33)\end{array}$ & $\begin{array}{c}\text { All ADRs/grade3-4 } \\
(n=33)\end{array}$ \\
\hline Asthenia & 3 100.0) & $2(66.7)$ & $0(0.0)$ & $8(57.1)$ & $2(66.7)$ & $3(75.0)$ & $18(54.5)$ & $10(30.3)$ \\
\hline Condition aggravated & $1(33.3)$ & $0(0.0)$ & $1(16.7)$ & $4(28.6)$ & $1(33.3)$ & $3(75.0)$ & $10(30.3) / 5(15.2)$ & \\
\hline Pyrexia & $2(66.7)$ & $1(33.3)$ & $1(16.7)$ & $3(21.4)$ & $0(0.0)$ & $1(25.0)$ & $8(24.2)$ & $4(12.1)$ \\
\hline Chest pain & $1(33.3)$ & $1(33.3)$ & $1(16.7)$ & $2(14.3)$ & $0(0.0)$ & $0(0.0)$ & $5(15.2)$ & \\
\hline Chills & $2(66.7)$ & $1(33.3)$ & $1(16.7)$ & $0(0.0)$ & $0(0.0)$ & $0(0.0)$ & $4(12.1)$ & $4(12.1)$ \\
\hline General health deterioration & $0(0.0)$ & $0(0.0)$ & $0(0.0)$ & $2(14.3)$ & $1(33.3)$ & $1(25.0)$ & $4(12.1) / 4(12.1)$ & \\
\hline Constipation & $2(66.7)$ & $0(0.0)$ & $1(16.7)$ & $5(35.7)$ & $0(0.0)$ & $1(25.0)$ & $9(27.3)$ & \\
\hline Nausea & $0(0.0)$ & $1(33.3)$ & $1(16.7)$ & $3(21.4)$ & $2(66.7)$ & $1(25.0)$ & $8(24.2)$ & $5(15.2)$ \\
\hline Vomiting & $1(33.3)$ & $1(33.3)$ & $2(33.3)$ & $2(14.3)$ & $1(33.3)$ & $0(0.0)$ & $7(21.2)$ & \\
\hline Diarrhoea & $0(0.0)$ & $2(66.7)$ & $1(16.7)$ & $1(7.1)$ & $0(0.0)$ & $1(25.0)$ & $5(15.2)$ & \\
\hline Dyspnoea & $2(66.7)$ & 1 (33.3) & $3(50.0)$ & $5(35.7)$ & $0(0.0)$ & $3(75.0)$ & $14(42.4) / 7(21.2)$ & \\
\hline Hyperglycaemia & $0(0.0)$ & $0(0.0)$ & $1(16.7)$ & $3(21.4)$ & $2(66.7)$ & $2(50.0)$ & $8(24.2) / 4(12.1)$ & \\
\hline Decreased appetite & $0(0.0)$ & $1(33.3)$ & $1(16.7)$ & $3(21.4)$ & $1(33.3)$ & $1(25.0)$ & $7(21.2)$ & \\
\hline Headache & $1(33.3)$ & $2(66.7)$ & $0(0.0)$ & $3(21.4)$ & $1(33.3)$ & $0(0.0)$ & $7(21.2)$ & \\
\hline Flushing & $0(0.0)$ & $0(0.0)$ & $0(0.0)$ & $1(7.1)$ & $2(66.7)$ & $3(75.0)$ & $6(18.2)$ & $5(15.2)$ \\
\hline Hypersensitivity & $0(0.0)$ & $0(0.0)$ & $1(16.7)$ & $8(57.1)$ & $0(0.0)$ & $0(0.0)$ & $9(27.3) / 5(15.2)$ & $9(27.3) / 5(15.2)$ \\
\hline Weight decreased & $0(0.0)$ & $1(33.3)$ & $0(0.0)$ & $5(35.7)$ & $0(0.0)$ & $0(0.0)$ & $6(18.2)$ & \\
\hline
\end{tabular}

Abbreviations: $A D R=$ adverse drug reactions; $A E=$ adverse events; $N=$ number of patients. A subject with more than one finding in a specific category was only counted once; percentages are based on the total number of subjects in each treatment group. The table is sorted by descending subject count. Infusion reactions related to YS110 treatment were further prevented by

corticosteroids premedication.

Table 3. Cycle 1 pharmacokinetics parameters (mean \pm s.d.) for YS110 administration

\begin{tabular}{|c|c|c|c|c|c|c|c|}
\hline Dose $\left(\mathrm{mg} \mathrm{kg}^{-1}\right)$ & $\begin{array}{c}\text { Dose } \\
\text { Schedule }\end{array}$ & Day & $T_{1 / 2}(\mathrm{~h})$ & $\begin{array}{c}C_{\max } \\
\left(\mu \mathrm{g} \mathrm{ml}^{-1}\right)\end{array}$ & $\begin{array}{c}\mathrm{AUC}_{0-168} \\
\left(\mathrm{~h} \times \mu \mathrm{g} \mathrm{ml}^{-1}\right)\end{array}$ & $\begin{array}{c}\mathrm{AUC}_{0-\infty} \\
\left(\mathrm{h} \times \mu \mathrm{gl}^{-1}\right)\end{array}$ & $\begin{array}{c}\mathrm{CL} \\
\left(\mathrm{ml} \mathrm{h}^{-1} \mathrm{~kg}^{-1}\right)\end{array}$ \\
\hline 0.4 & $\mathrm{Q} 2 \mathrm{~W}$ & $\begin{array}{r}1 \\
29\end{array}$ & $\begin{array}{c}\text { ND } \\
14.8 \pm N D\end{array}$ & $\begin{array}{c}\text { ND } \\
5.85 \pm N D\end{array}$ & $\begin{array}{c}\text { ND } \\
143 \pm N D\end{array}$ & $\begin{array}{c}\text { ND } \\
145 \pm N D\end{array}$ & $\begin{array}{c}N D \\
2.79 \pm N D\end{array}$ \\
\hline 2 & $\mathrm{Q} 2 \mathrm{~W}$ & $\begin{array}{r}1 \\
29\end{array}$ & $\begin{array}{l}36.4 \pm 12.2 \\
43.1 \pm 12.6\end{array}$ & $\begin{array}{l}39.0 \pm 9.94 \\
40.1 \pm 10.4\end{array}$ & $\begin{array}{l}1710 \pm 360 \\
2080 \pm 943\end{array}$ & $\begin{array}{l}1810 \pm 472 \\
2280 \pm 1110\end{array}$ & $\begin{array}{l}1.16 \pm 0.245 \\
1.03 \pm 0.435\end{array}$ \\
\hline 4 & Q1W & $\begin{array}{r}1 \\
15 \\
29\end{array}$ & $\begin{array}{l}46.6 \pm 1.69 \\
70.4 \pm N R \\
76.2 \pm N D\end{array}$ & $\begin{array}{l}72.5 \pm 27.1 \\
82.4 \pm N R \\
98.4 \pm N D\end{array}$ & $\begin{array}{l}4340 \pm 1030 \\
6000 \pm N R \\
7320 \pm N D\end{array}$ & $\begin{array}{l}4740 \pm 1140 \\
7450 \pm N R \\
9340 \pm N D\end{array}$ & $\begin{array}{l}0.876 \pm 0.206 \\
0.678 \pm N R \\
0.547 \pm N D\end{array}$ \\
\hline 6 & $\mathrm{Q} 1 \mathrm{~W}$ & $\begin{array}{r}1 \\
15 \\
29\end{array}$ & $\begin{array}{c}67.8 \pm 13.8 \\
93.7 \pm 27.4 \\
154 \pm N R\end{array}$ & $\begin{array}{l}150 \pm 22.9 \\
182 \pm 17.2 \\
205 \pm 23.6\end{array}$ & $\begin{array}{l}10300 \pm 1800 \\
15700 \pm 3470 \\
18400 \pm 4320\end{array}$ & $\begin{array}{l}12800 \pm 3250 \\
22800 \pm 8250 \\
39700 \pm N R\end{array}$ & $\begin{array}{l}0.490 \pm 0.116 \\
0.393 \pm 0.0793 \\
0.340 \pm 0.0814\end{array}$ \\
\hline
\end{tabular}

For the initial dose levels $\left(0.1,0.4,1\right.$ and $\left.2 \mathrm{mg} \mathrm{kg}^{-1}\right)$, YS110 was administered on a Q2W schedule on days 1, 15 and 29. As expected, the maximum concentrations of YS110 $\left(C_{\max }\right)$ on days 1 and 29 were proportional to the dose levels. However, calculated half-lives (1-2 days) were shorter than expected for a humanised antibody and serum concentrations were at or below detectable levels $\left(0.4 \mu \mathrm{g} \mathrm{ml}^{-1}\right)$ by 1 week post infusion. To maintain measurable YS110 trough concentrations between doses, dosing was increased to five doses on a Q1W schedule on days 1, 8, 15, 22 and 29 for dose levels 2,4 and $6 \mathrm{mg} \mathrm{kg}^{-1}$. $C_{\max }$ values on day 1 were roughly proportional to dose level. Mean half-lives increased with increasing dose levels, rising significantly from day 1 to day 15 to day 29 in the 2,4 and $6 \mathrm{mg} \mathrm{kg}^{-1}$ cohorts $(\sim 1, \sim 2$ and $\sim 3$ days, respectively), and resulting in drug accumulation between the doses (Table 3).
Impact from exposure to YS110 on anti-drug antibody (ADA) response appeared to be most pronounced in the $0.4 \mathrm{mg} \mathrm{kg}^{-1}$ dose cohort. The two subjects who were ADA positive on Day 29 of Cycle 1 had notably reduced exposure relative to the one ADA negative subject. There were no ADAs detected in the higher dose groups.

Efficacy. A secondary objective of the study was to evaluate for the potential anti-tumour activity of YS110 according to RECIST 1.0 criteria (or modified RECIST criteria for mesothelioma). No objective response was observed in the treated patients. However, stable disease per RECIST criteria as the best response was observed in 13 out of the 26 evaluable patients following the first cycle of treatment, as shown in the accompanying Waterfall Plot Chart (Supplementary Figure S2). Overall median PFS was 43 days 
Table 4. Time on YS110 treatment and median PFS of treated patients

\begin{tabular}{|l|c|c|c|c|}
\hline Cohorts & $\begin{array}{c}\text { Dose } \\
\text { levels } \\
\text { (mg kg }^{-1} \text { ) }\end{array}$ & $\begin{array}{c}\text { Cancer } \\
\text { types (n) }\end{array}$ & $\begin{array}{c}\text { Median } \\
\text { infusions } \\
\mathbf{N} \text { (min-max) }\end{array}$ & $\begin{array}{c}\text { Median PFS } \\
\text { days (min-max) }\end{array}$ \\
\hline Q2W & 0.1 & Meso (3) & $3(3)$ & $42(41-42)$ \\
\hline Q2W & 0.4 & $\begin{array}{c}\text { Meso (2) } \\
\text { RCC (1) }\end{array}$ & $18(3-20)$ & $223(40-273)$ \\
\hline Q2W & 1.0 & $\begin{array}{c}\text { Meso (2) } \\
\text { RCC (4) }\end{array}$ & $3(1-3)$ & $40(28-59)$ \\
\hline Q2W & 2.0 & $\begin{array}{c}\text { Meso (6) } \\
\text { RCC (4) }\end{array}$ & $3(1-27)$ & $57(13-399)$ \\
\hline Q1W & 2.0 & $\begin{array}{c}\text { Meso (3) } \\
\text { UTC (1) }\end{array}$ & $5(1-20)$ & $47(5-184)$ \\
\hline Q1W & 4.0 & Meso (3) & $4(3-5)$ & $32(22-59)$ \\
\hline Q1W & 6.0 & Meso (4) & $17.5(1-30)$ & $58(15-258)$ \\
\hline All & All & All & $4(1-30)$ & $43(5-399)$ \\
\hline
\end{tabular}

Abbreviations: Meso= malignant mesothelioma; PFS = progression-free survival duration; $\mathrm{RCC}=$ renal cell carcinoma; UTC $=$ urothelial carcinoma.

(Table 4) as determined by a Kaplan-Meier Plot (Supplementary Figure S3). However, PFS of 184-399 days was observed in 7 patients (five cases of mesothelioma and two cases of RCC) out of 26 cases (mesothelioma: 19 cases, RCC: 6 cases and urinary tract carcinoma: 1 case). Table 4 summarises the median number of infusions administered and median PFS according to the different dose levels and schedule.

\section{Pharmacodynamics}

Immunomonitoring. The CD26 immunophenotyping on peripheral T and NK lymphocyte subpopulations under YS110 treatment was validated by testing two different anti-CD26 mAb clones. Indeed, in the first 12 patients tested using the M-A261 mAb (BD Pharmingen), we observed a dramatic decrease of $\mathrm{CD}_{2} 6^{+}$cells consequently to YS110 administration, suggesting the lack of detection of the CD26 epitope due to YS110 binding. These results (not shown), led us to test in parallel another clone 5K78 (Santa Cruz Biotechnology) showing that $\mathrm{CD}^{+} 6^{+}$cells were still detectable under YS110 treatment. The validation of this antiCD26 mAb was ensured by competition and cross-blocking experiments using increasing dilutions of YS110 in the CD26 immunophenotyping assay demonstrating no modulation of $\mathrm{CD}^{2} 6^{+}$subpopulations using the $5 \mathrm{~K} 78$ clone in contrast to the first clone tested.

At baseline in our series of patients, the mean \pm s.d. $(n=33)$ absolute values $\left(\times 10^{6}\right.$ per $\left.\mathrm{ml}\right)$ of lymphocytes populations were $0.94(65.7 \%) \pm 0.64$ for $\mathrm{CD}^{+} \mathrm{CD}^{+}, 0.33(34.5 \%) \pm 0.26$ for $\mathrm{CD}^{+}$ $\mathrm{CD}^{+} \mathrm{T}$ cells and $0.17(8.2 \%) \pm 0.17$ for $\mathrm{CD} 3{ }^{-} \mathrm{CD} 16^{+/-} \mathrm{CD} 56^{+}$ NK cells. The mean percentage of $\mathrm{CD} 26^{+}$subpopulations in the T-CD4, T-CD8 and NK cells was $24.7 \%, 8.2 \%$ and $5.2 \%$, respectively with a significant inter-patient variability. After YS110 infusions, the levels of the various PBL subpopulations decreased at day 1 and 2 (i.e., 24-48 h following YS110 infusions), with a subsequent recovery at day 15 and 29 pre-infusion samples in most patients (Supplementary Table S3). This decline in different PBL subpopulations was more frequently observed in patients who received higher doses $\left(2,4\right.$ and $\left.6 \mathrm{mg} \mathrm{kg}^{-1}\right)$ of YS110. However, this trend was not statistically significant considering the inter-individual variations across the different dose levels.

Serum cytokines. At baseline and during YS110, no serum IL-2 production was detectable in any of the patients. Significant rise of the pro-inflammatory cytokines IL- 6 and TNF- $\alpha$ was detected at day 1 and 2 following the first infusion of YS110 at 0.4, 1 and $2 \mathrm{mg} \mathrm{kg}^{-1}$ at various levels, including the first patient with a grade 3 infusion reactions DLT (at the Q1W $1 \mathrm{mg} \mathrm{kg}^{-1}$ dose level).
Different kinetics of serum IL-6 and TNF- $\alpha$ production were observed in patients receiving $2 \mathrm{mg} \mathrm{kg}^{-1}$ of YS110, whereas low or undetectable levels were observed in patients receiving 4.0 and $6.0 \mathrm{mg} \mathrm{kg}^{-1}$ of YS110, likely due to the administration of systemic steroid prophylaxis.

sCD26 and DPPIV activity in sera. To determine serum levels of sCD26 protein and DPPIV enzyme activity in each cohort before and after administration of YS110, we developed an in-house ELISA assay for sCD26 and DPPIV using anti-human CD26 murine mAbs exhibiting no cross-reactivity with the therapeutic humanised anti-CD26 mAb YS110 (Dong et al, 1998; Ohnuma et al, 2015a).

As shown in Figure 2A, an increase in YS110 infusion dose was associated with decreased serum sCD26 level, particularly in the cohorts of patients treated at 2, 4 and $6 \mathrm{mg} \mathrm{kg}^{-1}$, with $\sim 80 \%$ decrease in sCD26 level. Moreover, as CD26 level reflects DPPIV enzyme activity in the serum, a similar reduction in DPPIV enzyme activity was observed (Figure 2B).

\section{DISCUSSION}

YS110 is the first, and currently the only CD26-directed mAb in clinical trial. This FIH study demonstrates that YS110 therapy exhibits a favourable safety profile and results in encouraging disease stabilisation in heavily pretreated CD26-positive MPM or RCC patients who had previously progressed on conventional standard therapies.

The spectrum of AEs, the most common of which were lowgrade asthenia, hypersensitivity, chills, pyrexia, nausea, vomiting and headache, was similar to that previously described with humanised mAbs treatment (Scott et al, 2012). Two DLTs were reported as SUSARs consisting in grade 3 infusion reactions that resolved with supportive treatment. As both patients had a history of allergies, the protocol was subsequently amended to include clinically relevant allergies as a new excluding criterion, and the administration of systemic steroid prophylaxis has been implemented prior to each infusion at all cycles to better control such infusion reactions. In this study, high rate of hyperglycaemia was observed in patients in the top dose cohorts, consistent with the well-known effect of corticosteroid on glucose levels. However, hyperglycaemia resolved soon after cessation of steroid administration, whereas YS110 was detected in sera, with decreased serum DPPIV activity. Taken together, it is probable that premedicated corticosteroid, but not YS110, induces the hyperglycaemia observed in the patient cohorts receiving higher drug doses. With these new modifications, dose escalation up to $6 \mathrm{mg} \mathrm{kg}^{-1}$ was possible as in four patients in this cohort were treated without DLTs. Per protocol, $6 \mathrm{mg} \mathrm{kg}^{-1}$ was the highest dose level tested although the MTD was not achieved. The dose level of $6.0 \mathrm{mg} \mathrm{kg}^{-1}$ of YS110 was decided by study investigators to be the RP2D.

Total lymphocyte counts, as well as levels of $\mathrm{CD}_{2} 6^{+}$ lymphocytes, fell at Day 2 below the baseline levels. However, total lymphocyte counts recovered to reach baseline level at Day 8 and thereafter. These data indicate that YS110 administration resulted in a decrease in levels of peripheral lymphocytes including the CD26-positive lymphocyte subset soon after drug administration, and it is probable that YS110-mediated suppression of peripheral lymphocyte levels, including the CD26-positive subset, resolved by as early as Day 8 . Moreover, we observed a decrease in the level of the CD26-positive subset of peripheral lymphocytes following administration of YS110 alone without steroid prophylaxis in the $0.1-2.0 \mathrm{mg} \mathrm{kg}^{-1}$ cohorts, as shown in Supplementary Table S3. Therefore, it is conceivable that YS110, but not premedication steroid, was responsible for the temporary effect on CD26-positive lymphocyte counts. 

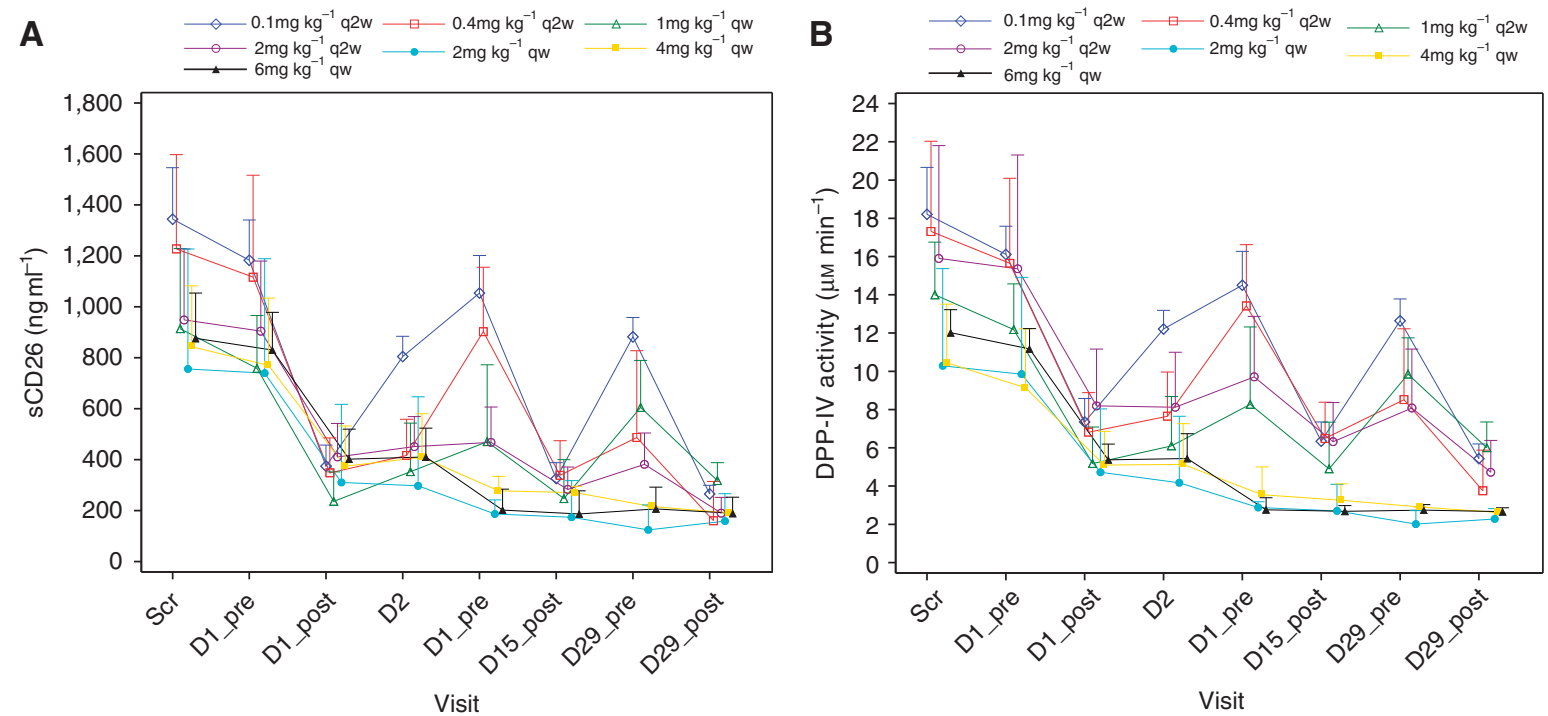

Figure 2. Changes of serum CD26/DPPIV levels following YS110 treatment: soluble CD26 (A) and DPPIV activity (B) mean \pm s.d. at cycle 1 at the different dose levels.

CD26 is also present in serum and other body fluids in a truncated form as sCD26/DPPIV, and our data also indicated that DPPIV enzyme activity decreased with increasing doses of YS110 (Figure 2B). Although DPPIV inhibitors are clinically used as oral hypoglycaemia agents (Barreira da Silva et al, 2015), hypoglycaemia was not observed during YS110 administration. Of note is the fact that $>80 \%$ inhibition of serum DPPIV activity was obtained $24 \mathrm{~h}$ after oral administration of clinically available DPPIV inhibitors (drug information published by each pharmaceutical company of sitagliptin, vildagliptin, saxagliptin and etc.), a level of inhibition comparable to that seen in patients treated with YS110. Our current data would therefore indicate that YS110 therapy is tolerable in the clinical setting.

The only treatment with level-one level of evidence for improving clinical outcome is the regimen consisting of a platinum doublet with an antifolate (van Meerbeeck et al, 2005). With this combined chemotherapy, patients with good performance status have a median overall survival of $\sim 1$ year, and a median PFS of $<6$ months. There is currently no standard second-line treatment with demonstrated ability to prolong survival. Importantly, patients who failed this first-line therapy have an extremely short survival (3.4 months), and are exposed to potentially lifethreatening toxicities unnecessarily (Blayney et al, 2012). Due to the lack of efficacy of conventional therapeutic approaches, it is potentially significant that treatment with YS110 results in encouraging disease stabilisation with a median PFS of 32 weeks (26-57 weeks) in seven heavily pretreated CD26-positive patients who previously progressed on conventional therapies (Supplementary Figures S2 and S3).

Recent work has demonstrated the functional role of DPPIV-mediated posttranslational modification of chemokines in regulating tumour immunity through its interaction with its substrate CXCL10 (Ohnuma et al, 2015b). Preservation of the full length, bioactive CXCL10 by DPPIV inhibition using the DPPIV inhibitor sitagliptin resulted in increased level of CXCR3 ${ }^{+}$effector $\mathrm{T}$ cells in the tumour microenvironment and subsequent tumour growth reduction (Ohnuma et al, 2015b). In view of these recent findings, data from our current trial showing that serum DPPIV activity was decreased following treatment with YS110 in a dosedependent manner (Figure 2B). It would suggest that anti-tumour activity via DPPIV inhibition may constitute yet another mechanism of action for the anti-tumour activity of YS110, in addition to the mechanisms of action discussed above (Hatano et al, 2015).

We recently reported that $\mathrm{CD} 3 / \mathrm{CD} 26$ costimulation induced the development of a human type $1 T_{\text {reg }}$ cells from CD $4^{+} \mathrm{T}$ cells with high level of IL-10 production and lymphocyte activation gene 3 (LAG3) expression (Nguyen and Ohashi, 2015). Preclinical models showed that antibody-mediated blocking of LAG3 as potential anti-cancer therapy led to enhanced activation of antigen-specific T cells at the tumour sites and disruption of tumour growth (Nishikawa et al, 2015). Moreover, anti-LAG3/ anti-PD-1 antibody treatment cured most mice of established tumours that were largely resistant to single antibody treatment (Nishikawa et al, 2015). Taken together, it is conceivable that CD26 itself may be a functional inhibitory molecule of an immune checkpoint system in certain disease conditions, similar to LAG3 or PD-1. In this scenario, CD26 blockade by YS110 may potentially function as an immune checkpoint blockade therapy, which can mediate anti-tumour activity in CD26-negative as well as CD26-positive cancers.

Microarray analyses of MPM cell lines treated with YS110 indicated that anti-CD26 mAb therapy resulted in the downregulation of cytochrome $c$ oxidase polypeptide I and II, and metallothione molecules that confer resistance to apoptosis or chemotherapeutic agents (Aoe et al, 2012). In addition, suppression of drug-resistant-related transporters, DNA repair enzyme and oncogenic protein expression was observed (Aoe et al, 2012). These preclinical results suggest that YS110 can function synergistically with other antineoplastic agents such as selected chemotherapeutic drugs to inhibit tumour growth.

Tumour surface expression of CD26/DPP4 may also have direct biological effects on the malignant behaviour of tumours. In several human malignancies including colorectal CRC, chronic myeloid leukaemia, gastric adenocarcinoma and MPM, CD26/DPP4 expression is reported to be a marker of cancer stem cells (Pang et al, 2010; Ghani et al, 2011; Yamazaki et al, 2012; Hatano et al, 2014; Herrmann et al, 2014; Davies et al, 2015). Given the potential role of CD26 surface expression in cancer biology, YS110 therapy may also influence tumour growth through its potential effect on the cancer stem cells of selected tumours.

In conclusion, our FIH study showed that YS110 therapy is generally well tolerated up to $6 \mathrm{mg} \mathrm{kg}^{-1} \mathrm{Q} 1 \mathrm{~W}$, which has been 
defined as the RP2D and results in encouraging disease stabilisation in a number of patients with advanced/refractory CD26expressing cancers. Our findings also suggest that further clinical development of YS110 such as its use as part of combination therapies with other antineoplastic agents is warranted.

\section{ACKNOWLEDGEMENTS}

This study was supported by Y'AC Co., Ltd, Tokyo, Japan, Kissei Pharmaceutical Co., Ltd, Tokyo, Japan and Japan Agency for Medical Research and Development (AMED).

\section{CONFLICT OF INTEREST}

Yutaro Kaneko is an employer of Y's AC Co., Ltd, Japan, Thomas Podoll is an employer of Y's Therapeutics Inc., USA, and Yu Kuramochi and Itaru Miyashita are the employees of Kissei Pharmaceutical Co., Ltd, Tokyo, Japan. Chikao Morimoto, Kei Ohnuma and Nam H Dang are stock holders of Y's AC Co., Ltd. The remaining authors declare no conflict of interest.

\section{REFERENCES}

Amatya VJ, Takeshima Y, Kushitani K, Yamada T, Morimoto C, Inai K (2011) Overexpression of CD26/DPPIV in mesothelioma tissue and mesothelioma cell lines. Oncol Rep 26: 1369-1375.

Aoe K, Amatya VJ, Fujimoto N, Ohnuma K, Hosono O, Hiraki A, Fujii M, Yamada T, Dang NH, Takeshima Y, Inai K, Kishimoto T, Morimoto C (2012) CD26 overexpression is associated with prolonged survival and enhanced chemosensitivity in malignant pleural mesothelioma. Clin Cancer Res 18: 1447-1456.

Barreira da Silva R, Laird ME, Yatim N, Fiette L, Ingersoll MA, Albert ML (2015) Dipeptidylpeptidase 4 inhibition enhances lymphocyte trafficking, improving both naturally occurring tumor immunity and immunotherapy. Nat Immunol 16: 850-858.

Blayney JK, Ceresoli GL, Castagneto B, O’Brien ME, Hasan B, Sylvester R, Rudd R, Steele J, Busacca S, Porta C, Mutti L, O’Byrne KJ, Scullin P, Gaafar R, Baas P, Van Meerbeeck J, Fennell DA (2012) Response to chemotherapy is predictive in relation to longer overall survival in an individual patient combined-analysis with pleural mesothelioma. Eur J Cancer 48: 2983-29892.

Dang NH, Torimoto Y, Deusch K, Schlossman SF, Morimoto C (1990a) Comitogenic effect of solid-phase immobilized anti-1F7 on human CD4 $\mathrm{T}$ cell activation via CD3 and CD2 pathways. J Immunol 144: 4092-4100.

Dang NH, Torimoto Y, Sugita K, Daley JF, Schow P, Prado C, Schlossman SF, Morimoto C (1990b) Cell surface modulation of CD26 by anti-1F7 monoclonal antibody. Analysis of surface expression and human T cell activation. J Immunol 145: 3963-3971.

Davies S, Beckenkamp A, Buffon A (2015) CD26 a cancer stem cell marker and therapeutic target. Biomed Pharmacother 71: 135-138.

Dong RP, Tachibana K, Hegen M, Scharpe S, Cho D, Schlossman SF, Morimoto C (1998) Correlation of the epitopes defined by anti-CD26 mAbs and CD26 function. Mol Immunol 35: 13-21.

Ghani FI, Yamazaki H, Iwata S, Okamoto T, Aoe K, Okabe K, Mimura Y, Fujimoto N, Kishimoto T, Yamada T, Xu CW, Morimoto C (2011) Identification of cancer stem cell markers in human malignant mesothelioma cells. Biochem Biophys Res Commun 404: 735-742.

Hatano R, Yamada T, Matsuoka S, Iwata S, Yamazaki H, Komiya E, Okamoto T, Dang NH, Ohnuma K, Morimoto C (2014) Establishment of monoclonal anti-human CD26 antibodies suitable for immunostaining of formalin-fixed tissue. Diagn Pathol 9: 30.

Hatano R, Ohnuma K, Otsuka H, Komiya E, Taki I, Iwata S, Dang NH, Okumura K, Morimoto C (2015) CD26-mediated induction of EGR2 and IL-10 as potential regulatory mechanism for CD26 costimulatory pathway. J Immunol 194: 960-972.
Havre PA, Abe M, Urasaki Y, Ohnuma K, Morimoto C, Dang NH (2008) The role of CD26/dipeptidyl peptidase IV in cancer. Front Biosci 13: 1634-1645.

Hegen M, Kameoka J, Dong RP, Schlossman SF, Morimoto C (1997) Cross-linking of CD26 by antibody induces tyrosine phosphorylation and activation of mitogen-activated protein kinase. Immunology 90: 257-264.

Herrmann H, Sadovnik I, Cerny-Reiterer S, Rulicke T, Stefanzl G, Willmann M, Hoermann G, Bilban M, Blatt K, Herndlhofer S, Mayerhofer M, Streubel B, Sperr WR, Holyoake TL, Mannhalter C, Valent P (2014) Dipeptidylpeptidase IV (CD26) defines leukemic stem cells (LSC) in chronic myeloid leukemia. Blood 123: 3951-3962.

Ho L, Aytac U, Stephens LC, Ohnuma K, Mills GB, McKee KS, Neumann C, LaPushin R, Cabanillas F, Abbruzzese JL, Morimoto C, Dang NH (2001) In vitro and in vivo antitumor effect of the anti-CD26 monoclonal antibody 1F7 on human CD30 + anaplastic large cell T-cell lymphoma Karpas 299. Clin Cancer Res 7: 2031-2040.

Inamoto T, Yamochi T, Ohnuma K, Iwata S, Kina S, Inamoto S, Tachibana M, Katsuoka Y, Dang NH, Morimoto C (2006) Anti-CD26 monoclonal antibody-mediated G1-S arrest of human renal clear cell carcinoma Caki-2 is associated with retinoblastoma substrate dephosphorylation, cyclindependent kinase 2 reduction, p27kip1 enhancement, and disruption of binding to the extracellular matrix. Clin Cancer Res 12: 3470-3477.

Inamoto T, Yamada T, Ohnuma K, Kina S, Takahashi N, Yamochi T, Inamoto S, Katsuoka Y, Hosono O, Tanaka H, Dang NH, Morimoto C (2007) Humanized anti-CD26 monoclonal antibody as a treatment for malignant mesothelioma tumors. Clin Cancer Res 13: 4191-4200.

Morimoto C, Torimoto Y, Levinson G, Rudd CE, Schrieber M, Dang NH, Letvin NL, Schlossman SF (1989) 1F7, a novel cell surface molecule, involved in helper function of CD4 cells. J Immunol 143: 3430-3439.

Morimoto C, Schlossman SF (1998) The structure and function of CD26 in the T-cell immune response. Immunol Rev 161: 55-70.

Nguyen LT, Ohashi PS (2015) Clinical blockade of PD1 and LAG3-potential mechanisms of action. Nat Rev Immunol 15: 45-56.

Nishikawa S, Konno M, Hamabe A, Hasegawa S, Kano Y, Fukusumi T, Satoh T, Takiguchi S, Mori M, Doki Y, Ishii H (2015) Surgically resected human tumors reveal the biological significance of the gastric cancer stem cell markers CD44 and CD26. Oncol Lett 9: 2361-2367.

Ohnuma K, Dang NH, Morimoto C (2008) Revisiting an old acquaintance: CD26 and its molecular mechanisms in T cell function. Trends Immunol 29: 295-301.

Ohnuma K, Hosono O, Dang NH, Morimoto C (2011) Dipeptidyl peptidase in autoimmune pathophysiology. Adv Clin Chem 53: 51-84.

Ohnuma K, Saito T, Hatano R, Hosono O, Iwata S, Dang NH, Ninomiya H, Morimoto C (2015a) Comparison of two commercial ELISAs against an in-house ELISA for measuring soluble CD26 in human serum. J Clin Lab Anal 29: 106-111.

Ohnuma K, Hatano R, Morimoto C (2015b) DPP4 in anti-tumor immunity: going beyond the enzyme. Nat Immunol 16: 791-792.

Okamoto T, Iwata S, Yamazaki H, Hatano R, Komiya E, Dang NH, Ohnuma K, Morimoto C (2014) CD9 Negatively regulates CD26 expression and inhibits CD26-mediated enhancement of invasive potential of malignant mesothelioma cells. PLoS ONE 9: e86671.

Pang R, Law WL, Chu AC, Poon JT, Lam CS, Chow AK, Ng L, Cheung LW, Lan XR, Lan HY, Tan VP, Yau TC, Poon RT, Wong BC (2010) A subpopulation of CD26 + cancer stem cells with metastatic capacity in human colorectal cancer. Cell Stem Cell 6: 603-615.

Scott AM, Wolchok JD, Old LJ (2012) Antibody therapy of cancer. Nat Rev Cancer 12: 278-287.

Tanaka T, Kameoka J, Yaron A, Schlossman SF, Morimoto C (1993) The costimulatory activity of the CD26 antigen requires dipeptidyl peptidase IV enzymatic activity. Proc Natl Acad Sci USA 90: 4586-4590.

Torimoto Y, Dang NH, Tanaka T, Prado C, Schlossman SF, Morimoto C (1992) Biochemical characterization of CD26 (dipeptidyl peptidase IV): functional comparison of distinct epitopes recognized by various antiCD26 monoclonal antibodies. Mol Immunol 29: 183-192.

van Meerbeeck JP, Gaafar R, Manegold C, van Klaveren RJ, van Marck EA, Vincent M, Legrand C, Bottomley A, Debruyne C, Giaccone G (2005) Randomized phase III study of cisplatin with or without raltitrexed in patients with malignant pleural mesothelioma: an intergroup study of the European Organisation for Research and Treatment of Cancer Lung Cancer Group and the National Cancer Institute of Canada. J Clin Oncol 23: $6881-6889$. 
Yamada K, Hayashi M, Madokoro H, Nishida H, Du W, Ohnuma K, Sakamoto M, Morimoto C, Yamada T (2013) Nuclear localization of CD26 induced by a humanized monoclonal antibody inhibits tumor cell growth by modulating of POLR2A transcription. PLoS One 8: e62304.

Yamamoto J, Ohnuma K, Hatano R, Okamoto T, Komiya E, Yamazaki H, Iwata S, Dang NH, Aoe K, Kishimoto T, Yamada T, Morimoto C (2014) Regulation of somatostatin receptor 4-mediated cytostatic effects by CD26 in malignant pleural mesothelioma. Br J Cancer 110: 2232-2245.

Yamazaki H, Naito M, Ghani FI, Dang NH, Iwata S, Morimoto C (2012) Characterization of cancer stem cell properties of CD24 and
CD26-positive human malignant mesothelioma cells. Biochem Biophys Res Commun 419: 529-536.

(c) (1) (2) (2) This work is licensed under the Creative Commons At Ac SA Atribution-Non-Commercial-Share Alike 4.0 International License. To view a copy of this license, visit http:// creativecommons.org/licenses/by-nc-sa/4.0/

(C) The Author(s) named above 2017

Supplementary Information accompanies this paper on British Journal of Cancer website (http://www.nature.com/bjc) 